\title{
UNA VERSIÓN PRAGMATISTA DEL CONCEPTO DE RESPONSABILIDAD MORAL
}

\author{
JAVIER HERNÁNDEZ \\ Departamento de Humanidades \\ Universidad Carlos III de Madrid \\ jhiglesi@hum.uc3m.es
}

\author{
"En el principio era la acción $[\ldots] "$ \\ J.W. Goethe, Fausto
}

RESUMEN: El objetivo de este trabajo es justificar la relevancia del uso, en filosofía moral, de un concepto de responsabilidad moral vinculado a la idea de libre albedrío, independientemente del carácter determinista o indeterminista de la acción humana. Así, siguiendo la estela de P.F. Strawson, se propone una interpretación pragmatista del concepto de responsabilidad moral basada en el hecho de que normalmente los seres humanos funcionamos moralmente haciendo atribuciones de responsabilidad. Se defiende pues la vicariedad desde el punto de vista práctico del debate metafísico entre compatibilistas e incompatibilistas, y se argumenta a favor de una teoría de la responsabilidad moral como elección racional a la luz de nuestras prácticas morales cotidianas.

PALABRAS CLAVE: determinismo, libertad, racionalidad, acción

SUMMARY: This paper aims to defend a possible use of the concept of responsibility in moral philosophy — which is linked to the idea of free willdisregarding the deterministic and indeterministic character of human action. Thus, following P.F. Strawson, a pragmatist interpretation of the concept of moral responsibility is proposed, which is based on the fact that normally human beings act morally in making ascriptions of responsibility. Here, I defend that the metaphysical debate between compatibilism and incompatibilism is vicarious from a practical point of view, and some arguments are offered to sustain a theory of moral responsibility as something rational to defend in the light of our daily moral practices.

KEY WORDS: determinism, free will, rationality, action

\section{Introducción: el problema del libre albedrio}

Tradicionalmente el problema del libre albedrío ha llevado consigo, al menos, dos grandes preguntas. Por un lado, la pregunta acerca de la naturaleza determinada o indeterminada de la acción humana y, por otro, la pregunta acerca de la compatibilidad 
o incompatibilidad entre la libertad y el determinismo. Teniendo en cuenta que éstas son las dos grandes preguntas asociadas al problema del libre albedrío, podría decirse que aquí no me ocuparé directamente de dicho problema, sino de una tercera pregunta que a menudo depende de las otras dos, a saber: ¿somos los seres humanos moralmente responsables?

Aquí sostendré que es posible responder a esta pregunta sin hacerse eco del debate entre deterministas e indeterministas y entre compatibilistas e incompatibilistas. Sin duda, ambos debates son relevantes para la filosofía moral y su solución acarrearía ciertas consecuencias no sólo en nuestra forma de entender la moral, sino también en nuestra forma de practicarla, esto es, de funcionar moralmente. No obstante, a menudo se ha exagerado la importancia del problema determinismo/libertad desde un punto de vista práctico y se ha concluido que es imposible justificar la racionalidad de nuestro comportamiento como seres responsables al margen del problema del libre albedrío. La tarea que aquí emprendo es justificar racionalmente, a partir de una lectura pragmatista de la racionalidad, nuestro funcionamiento como seres moralmente responsables, sea nuestra acción determinada o indeterminada.

\section{Dos formas de entender la racionalidad}

En su indispensable artículo "Freedom and Resentment", P.F. Strawson aporta, entre otros, el siguiente argumento a favor de la racionalidad del uso del concepto de responsabilidad moral:

Podríamos escoger racionalmente sólo a la luz de una valoración de las ganancias y pérdidas para la vida humana, su enriquecimiento o empobrecimiento; y la verdad o la falsedad de una tesis general del determinismo no podría menoscabar la racionalidad de esta elección. (Strawson 1962, pp. 55-56) ${ }^{1}$

Podemos decir que en este argumento está presente una idea de racionalidad que podríamos denominar racionalidad prác-

${ }^{1}$ En todas las citas, las traducciones son mías. 
tica. En su artículo, Strawson intenta convencernos de que desde el punto de vista práctico no sería racional que prescindiésemos del concepto de responsabilidad moral porque ello implicaría tener que dejar de lado ciertos rasgos de nuestro comportamiento social, en particular, deberíamos abandonar gran parte de nuestras emociones, lo cual supondría una clara merma en nuestra calidad de vida.

Aunque el principio sobre el que reposa este argumento, a saber, que nada está por encima de la riqueza de nuestra vidas, es alentador, dista de ser indiscutible, por lo menos desde la perspectiva de la racionalidad. Claramente existe un segundo tipo de racionalidad, que podríamos llamar racionalidad epistémica, por la cual "la racionalidad de una actitud no se mide por las probables consecuencias de adoptarla sino por la vigencia de las creencias que entran dentro de ella" (Ayer 1980, p. 11). Este tipo de racionalidad reposa en un compromiso con la verdad y nos dice que nuestras prácticas no están justificadas a menos que sean coherentes con nuestras ideas, y esto independientemente de lo enriquecedoras que dichas prácticas puedan ser para nuestras vidas.

Así pues, en el seno del incompatibilismo existe un conflicto de compromisos: uno práctico con una forma de vida y otro teórico con la coherencia de nuestras acciones respecto de nuestras creencias. Este conflicto es característico de aquel que cree que el determinismo es cierto e incompatible con la libertad, y aquí asumiremos que su postura es correcta.

Ciertamente los filósofos tendemos a pensar que el compromiso más importante es el que mantenemos con la verdad. Sin ir más lejos, si somos ateos y hemos conseguido demostrarle a alguien que, desde el punto de vista teórico, no hay ninguna razón, por la cual se deba creer en Dios, cuando nuestro interlocutor nos responde que es más feliz creyendo en Dios, así que le es indiferente que dicha creencia sea falsa, consideraremos que el suyo es un argumento de baja estofa. Sin embargo, debemos preguntarnos si este argumento realmente responde a un compromiso genuino con la racionalidad práctica. 
Con anterioridad hemos señalado que el compromiso con la racionalidad práctica implica un compromiso con una forma de vida, el problema está en saber qué queremos decir con "forma de vida". Si por "forma de vida" no entendemos más que, por ejemplo, ciertas prácticas o ritos que tranquilizan nuestra conciencia y que nos permiten vivir sin temor a la muerte, entonces evidentemente el argumento de Strawson a favor del concepto de responsabilidad moral no es bueno. Ahora bien, si lo que entendemos por "forma de vida" no es sólo un conjunto de prácticas sino todo un entramado dotado de sentido sin el cual somos incapaces de funcionar, entonces lo que Strawson nos estaría diciendo es que hay cosas a las que no podemos renunciar, porque sin ellas se disgrega nuestra vida, y que eso está por encima de cualquier compromiso de orden teórico.

Naturalmente aquí hemos dado un salto importante del cual debo dar cuenta y voy a hacerlo retomando el ejemplo de nuestro creyente incorregible. Es posible que el creyente se sienta incapaz de vivir sin creer en Dios; sin embargo, que un buen número de gente sea atea y además feliz, incluso más que muchos creyentes, demuestra que el convencimiento del creyente no es sino autoengaño, y que la creencia en Dios, que no es en absoluto necesaria para llevar una vida feliz, en muchos casos resulta hasta contraproducente. Ahora cabe preguntarse si mantener la existencia de la responsabilidad moral es una creencia del mismo orden que la creencia en Dios. Lo que está claro es que existe una alternativa a la creencia en Dios y que dicha alternativa no supone un empobrecimiento de nuestras vidas; no está tan claro, empero, si existe una alternativa real a la existencia de la responsabilidad moral. Naturalmente, el determinista incompatibilista dirá que sí, que el que no exista la responsabilidad moral es una alternativa, y desde luego lo es; pero tenemos que averiguar si esa alternativa es algo más que una alternativa teórica, esto es, si lleva consigo realmente una forma de vida que pueda venir a sustituir provechosamente a la que actualmente tenemos y que está basada en el concepto de responsabilidad moral. 


\section{Nuestro compromiso con la responsabilidad moral}

Uno de los puntos claves del artículo de Strawson es que señala que a menudo atribuimos responsabilidad mediante emociones que él llama "actitudes reactivas". Se trataría de emociones como la indignación, la gratitud o la culpa. Dichas emociones constituyen un juicio sobre expectativas que depende directamente de nuestras atribuciones de responsabilidad moral. Así, si sentimos indignación hacia alguien es porque lo consideramos responsable de haber defraudado alguna expectativa que habíamos volcado en él. No obstante, hay ocasiones en que resulta apropiado suspender nuestras emociones reactivas hacia alguien, porque consideramos que dicha persona no es un sujeto apropiado para nuestras expectativas. Tal es el caso de un enfermo mental que no sabe lo que hace o de alguien que actúa bajo coerción. En esos casos decimos que el agente tiene una excusa o que se le exime de responsabilidad.

Sin embargo, Strawson señala que esta suspensión de nuestras emociones reactivas sólo tiene sentido como excepción a nuestra forma normal de comportarnos socialmente, esto es, volcando expectativas en los demás y juzgándolos por la responsabilidad de sus acciones según respondan o no a nuestras expectativas. Así, podemos decir que el argumento que Strawson maneja para defender la forma en que habitualmente usamos el concepto de responsabilidad moral sería algo parecido a esto: nuestro comportamiento social depende de manera insustituible del concepto de responsabilidad moral; únicamente podemos suspender las atribuiciones de responsabilidad moral en casos que constituyen una anomalía en nuestro funcionamiento social normal. Y a esto Strawson añade la siguiente apreciación: "que la anormalidad sea la condición universal no puede ser consecuencia de ninguna tesis que no sea ella misma contradictoria" (Strawson 1962, pp. 53-54).

Por lo tanto, en el caso de la responsabilidad moral, una de las estrategias que se pueden seguir para mostrar la prioridad de nuestro compromiso práctico con una forma de vida (actuar realizando atribuciones de responsabilidad), por encima de nuestro compromiso teórico con una creencia (que determi- 
nismo y responsabilidad son incompatibles), sería sostener que nuestro comportamiento como seres moralmente responsables es independiente de esa creencia. Sencillamente es así y pretender lo contrario supone aspirar a universalizar lo que es un comportamiento que sólo tiene sentido si es considerado una excepción, una anormalidad dentro del entramado general de nuestro comportamiento social.

Esta estrategia lleva consigo una apuesta metafísica muy fuerte, pues implica que el hecho de que nos comportemos conforme al concepto de responsabilidad moral no es accidental, sino necesario. Lo que Strawson parece decir es que nuestras creencias son irrelevantes en materia de responsabilidad porque naturalmente tendemos a comportarnos como seres responsables y nada podría hacer que dejásemos de comportarnos como tales, mucho menos una exigencia en el orden de la racionalidad epistémica.

Así pues, según Strawson, nuestro compromiso práctico con la responsabilidad moral es, por naturaleza, anterior a nuestro compromiso teórico con la idea de que el determinismo y la libertad y, por ende, la responsabilidad moral son incompatibles.

Es el momento de recuperar a nuestro afamado creyente y ver si su argumento a favor de su creencia en Dios puede reelaborarse tal y como lo he hecho con el argumento de Strawson a favor de la responsabilidad moral. No podemos por menos que concluir que no, pues existe una multitud de contraejemplos. En efecto, ningún creyente puede decirnos que es imposible vivir sin creer en Dios, pues es un hecho que mucha gente lo hace. Ahora, preguntémonos una cosa: ¿no es posible que Strawson considere que es irrenunciable la forma de vida que implica el concepto de responsabilidad moral porque no existen contraejemplos, porque no hay nadie que hasta hoy haya sido capaz de vivir sin realizar atribuciones de responsabilidad? Ciertamente sostener que no se debe (o incluso no se puede) renunciar al uso del concepto de responsabilidad moral porque ello, de hecho, sólo se da como anomalía dentro del juego de expectativas que actualmente conforma nuestra vida social, tiene visos de ser una falacia naturalista. Cabe preguntarse si aquel que dice que la responsabilidad moral es un concepto 
del cual no podemos prescindir para vivir en sociedad no está diciendo nada diferente de aquel que sostiene que sin creer en Dios no se puede vivir. En fin, todavía no he dilucidado si nuestro compromiso con la responsabilidad moral es o no necesario. Para lograrlo voy a crear, en términos de Daniel Dennett, un "generador de intuición" que nos mostrará hasta qué punto nos es o no imprescindible el concepto de responsabilidad moral.

Imaginemos otro mundo posible, Determinilandia, donde la ciencia ha proporcionado todas las leyes de la psicología humana. Los científicos son capaces de predecir con éxito nuestras acciones tras un análisis pormenorizado de nuestras redes neuronales. Es más, la tecnología ha avanzado tanto que los científicos han sido capaces de diseñar un casco, el Predictor, que va conectado al cerebro y que puede traducir nuestros impulsos nerviosos al lenguaje natural y especificar cuáles son nuestras creencias y nuestros deseos en todo momento. Este casco, en cuya elaboración han colaborado unos eminentes sociólogos positivistas, es además capaz de dar cuenta de las influencias del medio social en nuestras redes neuronales y de reinterpretar el sistema de creencias y deseos del individuo portador del casco con base en dichas influencias externas. Pues bien, las cosas están del siguiente modo: en Determinilandia todas las personas llevan acoplado, desde la niñez, un Predictor. Así pues tenemos un mundo en el que es posible predecir con éxito qué va a hacer cada uno en todo momento con sólo mirar un pequeño marcador que el Predictor lleva adaptado y en el que se reflejan sus creencias y deseos. La pregunta es: ¿Qué sentido tendría seguir manejando el concepto de responsabilidad moral en Determinilandia?

De forma intuitiva lo normal es pensar que en Determinilandia no hay razón alguna para que hagamos atribuciones de responsabilidad porque para cada acción, gracias al Predictor, somos capaces de rastrear todas y cada una de las causas tanto psicológicas como sociales que la determinan. Así, nunca diríamos "Afrodisio es responsable de haber matado a ese perro", sino, más bien, "Afrodisio tuvo una descarga del neurotransmi- 
sor $x$ que provocó que matase a ese perro, su propensión a descargar ese neurotransmisor en presencia de un perro es fruto de los episodios $y, z$ y $f$ que tuvieron lugar en los momentos $v, h$ y $t$ de su vida en que recibió y asimiló las normas culturales $H 501$ y N334." En definitiva, todo acto sería explicable mediante una ley natural concreta que constaría de unas variables tipificadas científicamente, y en esas circunstancias explicaríamos todas y cada una de nuestras acciones en términos de leyes científicas y no de acción responsable. Tal vez hablaríamos metafóricamente de acción, tal y como hoy lo hacemos con la marea, por ejemplo, cuando decimos que sube o baja, pero no haríamos juicios sobre responsabilidad. O tal vez sí, pero en cualquier caso cabe pensar que no lo haríamos, y con esa posibilidad me es suficiente para aquello que pretendía mostrar con este experimento mental: que no hay nada contradictorio en pensar que podríamos funcionar socialmente sin recurrir al concepto de responsabilidad moral. Dicho de otro modo: no está justificada la idea de Strawson, y de otros muchos defensores del compatibilismo, de que nada, y en concreto ninguna exigencia de orden teórico, lograría nunca y en ninguna circunstancia hacernos dejar de lado nuestro uso habitual del concepto de responsabilidad moral. Por ello puedo concluir que, efectivamente, sostener que nuestro comportamiento como seres responsables es insoslayable es fruto de una falacia naturalista, pues nada nos permite deducir del hecho de que hasta hoy nadie haya sido capaz de soslayarlo el que nunca nadie y en ninguna circunstancia vaya a ser capaz de hacerlo. Ahora bien, el hecho bastante palpable de que ningún determinista incompatibilista haya sido capaz de renunciar a su comportamiento como persona responsable es suficientemente importante como para que nos preguntemos por sus fundamentos.

Anteriormente señalé que había dos tipos de racionalidad y el problema que vimos con respecto a la responsabilidad moral era que, si somos deterministas e incompatibilistas, entonces debemos optar por comprometernos o bien con la racionalidad práctica del uso del concepto de responsabilidad moral o bien con su racionalidad epistémica, pues ambos compromisos son, 
en ese caso, incompatibles. Lo que advertimos si analizamos el caso de los seres que pueblan Determinilandia es que ellos no tienen ese conflicto de compromisos, sino que su racionalidad práctica y su racionalidad epistémica con respecto al uso del concepto de responsabilidad moral coinciden perfectamente. ¿Cuáles son las circunstancias que hacen eso posible y cuáles deberían ser las cosas que habrían de cambiar en nuestro mundo para que se diese tal coincidencia en nuestras racionalidades?

El caso es que en Determinilandia se cuenta con una definición del determinismo mucho mejor que la que poseemos hoy en día. En efecto, su definición del determinismo no se expresa sólo desde el punto de vista teórico, sino también desde el punto de vista práctico mediante "leyes manejables",2 esto es, leyes que permiten usar el determinismo de forma predictiva y realmente explicativa en nuestra vida social. En la actualidad contamos con una definición del determinismo que permite hacer predicciones y que suministra explicaciones muy precisas en el ámbito de las ciencias naturales y, por ello, no le atribuimos responsabilidad a la piedra que cae o al viento que abre la puerta. Ahora bien, si llegásemos a descubrir cómo se forjan todas y cada una de las acciones de los seres humanos y a describirlas del mismo modo en que somos capaces de hacerlo con las piedras y con las corrientes, entonces es muy probable que lo más racional tanto desde el punto de vista teórico como desde el punto de vista práctico fuera explicar el comportamiento humano con base en descripciones científicas y no en términos de responsabilidad moral. Así pues no puedo afirmar que haya algo que nos permita pensar que la responsabilidad moral es un aspecto irrenunciable de la naturaleza humana.

Sin embargo, en este artículo quiero defender que el uso del concepto de responsabilidad moral está justificado, que no hay ninguna razón suficiente para que lo abandonemos y que esto

\footnotetext{
${ }^{2}$ Con respecto a un determinismo expresado en "leyes manejables", véase A.J. Ayer 1980.
} 
es así porque hoy por hoy debe primar nuestro compromiso práctico con nuestra actual forma de vida sobre el compromiso teórico del incompatibilista con sus presupuestos epistémicos. Para mostrar esto primero me detendré a analizar en qué consiste el juego de la responsabilidad moral como forma de vida y más adelante me pronunciaré sobre la racionalidad de seguir con ese juego.

\section{La responsabilidad como trasfondo}

Nuestra responsabilidad se define, se crea, intersubjetivamente, mediante la interacción con los demás. Hay ocasiones en que esa interacción se ve frustrada y entonces usamos excusas o eximimos de responsabilidad, pero esto sucede como excepción y precisamente por serlo somos capaces de considerarlo anormal, porque altera nuestra forma común de comportarnos en sociedad, nuestras "relaciones interpersonales normales". ${ }^{3}$ En este sentido, el incompatibilista es una especie de extraterrestre, incapaz de comunicarse correctamente. Puede decirse que la creencia en el determinismo y la convicción incompatibilista, una vez formuladas, no son sino excusas sin sentido, constituyen un mal uso del lenguaje o un síntoma de que éste no se entiende bien: "Sólo el contexto habitual hace posible que se muestre con claridad lo que se quiere decir" (Wittgenstein 1988, § 237, p. 31c).

En efecto, imaginemos una conversación en la que un incompatibilista trata de convencer a sus vecinos de que no es responsable de haber atropellado al perro de éstos porque sencillamente la libertad no existe y, por lo tanto, él no es responsable de nada. Seguramente lo primero que los vecinos del canicida incompatibilista pensarían cuando éste les dijera "No soy responsable de haber atropellado a su perro" sería que no fue realmente él quien lo atropelló, sino otra persona. Sin embargo, entonces nuestro incompatibilista diría: "No, hombre. Por supuesto que yo lo atropellé. Pero no soy responsable de ello." Con un ligero estupor, los dueños del malogrado animal

\footnotetext{
${ }^{3}$ La expresión es de P.F. Strawson.
} 
dirían entonces: "¿Se cruzó en su camino sin que usted pudiese esquivarlo?", o quizá "¿No tuvo más remedio que atropellarlo para esquivar a un niño imprudente que se metió en la carretera?", o tal vez "¿Tuvo un ligero desmayo, fue incapaz de verlo?" En fin, los vecinos buscarían cualquier tipo de excusa realmente válida, esto es, con sentido en su lenguaje, en su mundo (que es el nuestro). Pero el incompatibilista se empeñaría en dar la única excusa que no tiene ningún sentido en ese (este) lenguaje: "No. No soy responsable del atropello porque no pude obrar de otro modo, y esto porque nunca puedo obrar de otro modo que como obro efectivamente, porque nunca soy responsable de mis actos." Los vecinos entonces dudarían entre llamar directamente a un manicomio o seguir con esa estúpida conversación, pero como hasta ese momento su vecino, dejando al margen el hecho de que era filósofo, les había parecido alguien muy normal, con envidiable buena fe seguirían preguntando: "¿Toma usted medicación? ¿Está usted enfermo y no sabe lo que hace?" Llegado ese punto, sin duda nuestro incompatibilista se indignaría y diría vehementemente: “¿Ustedes no entienden nada! Nadie es responsable de nada, no existe la libertad." A partir de aquí podrían suceder dos cosas: o bien los dueños del difunto perro, que leen la Ética de Spinoza en sus ratos libres, recordarían que todos estamos determinados y no somos metafísicamente libres, o bien llamarían a la policía. El resultado, antes o después, de cualquiera de estos dos hechos acabaría siendo el mismo: el incompatibilista nunca llegaría a ser capaz de usar el incompatibilismo como excusa que le permitiese eludir su responsabilidad. Intentar hacerlo es jugar mal el juego en el que todos estamos inmersos, es no participar del mismo mundo. Lo normal sería pensar que el incompatibilista no está en sus cabales o que no comprende bien el idioma. Tal vez los vecinos, grandes lectores de Spinoza como ya sabemos, disfrutarían un momento discutiendo sobre metafísica con nuestro incombustible incompatibilista, pero a la larga no dejarían de juzgarlo responsable de la muerte de su perro aunque es muy posible que al final lo dejasen ir en paz por considerarlo un lunático. Lo más probable es que acabasen rayándole el coche y mudándose. 
Ésta es una historia divertida (si obviamos la muerte del pobre perro), pero el problema que plantea es serio. Nuestro sistema de excusas y exenciones requiere una competencia interpretativa de carácter lingüístico y

ese proceso interpretativo asume que las acciones de un agente tienen lugar dentro de un medio social. Un agente debe comprender que dentro de ese medio social, a una acción-tipo se le asigna convencionalmente un significado normalmente indicativo de cierto tipo de motivo. Esto no sugiere que cada uno deba conformar sus acciones particulares a una interpretación asignada a alguna acción-tipo; sólo sugiere que si nuestras acciones han de divergir de esas interpretaciones, sus variaciones deben ser de alguna manera una función del entramado interpretativo en que operemos. (McKenna 1998a, p. 4)

El determinismo metafísico no es una función dentro de ese entramado y por ello el incompatibilismo no funciona como una excusa. Está directamente fuera del mundo de expectativas cumplidas e incumplidas en que nos movemos; para cobrar sentido necesita un mundo diferente, otro entramado interpretativo. El incompatibilista emite oraciones sin sentido porque pretende que éstas tengan un sentido distinto del que la sociedad les ha dado intersubjetivamente, y fuera de ese sentido no hay nada "no tengo mi imagen del mundo porque me haya convencido a mí mismo de que sea la correcta; ni tampoco porque esté convencido de su corrección. Por el contrario, se trata del trasfondo que me viene dado y sobre el que distingo entre lo verdadero y lo falso" (Wittgenstein 1988, § 94, p. 15c).

Desde la versión pragmatista de la racionalidad que aquí se defiende, se puede equiparar nuestra autopercepción como seres libres y responsables con nuestra creencia de que el mundo exterior existe. Así la responsabilidad pasa a formar parte de nuestra imagen del mundo, a ser algo que nos acompaña en todo momento, algo que somos y, sobre todo, algo que nos permite actuar. Esto último, si seguimos a Wittgenstein, convierte la responsabilidad en una evidencia pues "una evidencia segura es la que se supone incondicionalmente segura, algo de 
acuerdo con lo que actuamos con seguridad, sin duda alguna" (1988, § 196, p. 27c). Cierto, la filosofía lleva siglos dedicándose a desmontar evidencias, "sin embargo, la fundamentación, la justificación de la evidencia tiene un límite; - pero el límite no está en que ciertas proposiciones nos parezcan verdaderas de forma inmediata, como si fuera una especie de ver por nuestra parte; por el contrario, es nuestra actuación la que yace en el fondo del juego del lenguaje" (1988, § 204, p. 28c). Así, mientras el incompatibilista no sea capaz de actuar conforme al juego del lenguaje que pretende inventar, a la imagen del mundo alternativa que propone (Determinilandia), no puede decirse que realmente esa imagen exista más que como un mal uso del lenguaje, como una mala comprensión de la imagen del mundo que maneja. $\mathrm{O}$ ni siquiera eso: en tanto el incompatibilista actúa responsablemente y hace atribuciones de responsabilidad está demostrando que comprende la imagen del mundo en que somos seres responsables, es más, actuar responsablemente es lo mismo que creer en la responsabilidad y comprenderla: "Nuestro hablar obtiene su sentido del resto de nuestra actuación" (Wittgenstein 1988, §229, p. 30c).

Siguiendo esta perspectiva pragmatista, Michael McKenna dice:

la capacidad para actuar como un agente moralmente responsable puede ser entendida en analogía con el dominio de un hablante competente de un lenguaje natural. [...] si el determinismo amenazase la capacidad para actuar como un agente moralmente responsable, amenazaría también la capacidad del agente para dominar y hacer uso de un lenguaje natural. En tanto parece que el determinismo no supone esa amenaza para el uso competente del lenguaje, de un modo similar podría argumentarse que el determinismo no supone ninguna amenaza para la responsabilidad moral. (McKenna 1998a, p. 6)

Mientras, mediante nuestra capacidad para obrar en consecuencia, mostremos que comprendemos lo que significa la responsabilidad, el incompatibilismo no será un problema realmente peligroso para nuestra vida práctica. La duda incompatibilista 
tendría sentido si nos inhabilitase para seguir actuando como actuamos normalmente en nuestras relaciones interpersonales diarias; pero no lo hace, y esto se debe a que no tiene sentido en nuestro contexto vital, en nuestro mundo moral regido por el concepto de responsabilidad. Y no se puede formular fuera de él:

La cualidad moral del motivo de un agente requiere que el agente formule ese motivo dentro de un contexto interpretativo. Ese contexto está determinado por un conjunto de convenciones sociales que estructuran y mantienen una asociación de diferentes tipos de acciones y diferentes tipos de motivos. Del mismo modo en que un hablante competente es capaz de usar un lenguaje para expresar sus propios pensamientos, un agente moralmente competente es capaz de formar sus propios motivos moralmente imponibles sólo si posee un dominio suficiente de las convenciones que asignan interpretaciones de motivos-tipo a acciones-tipo. (McKenna 1998a, pp. 6-7)

Así pues, en el mejor de los casos ser incompatibilista sería un juego especulativo intelectual; en el peor una falta de dominio de las convenciones que nos permiten relacionarnos normalmente con los demás en nuestro mundo moral. Los incompatibilistas suelen ser personas cabales y bien integradas en la sociedad (en la medida en que puede estarlo un filósofo), por ello debemos entender el incompatibilismo como una hipótesis de otro mundo posible, como un experimento mental similar al de Determinilandia. Entendido de esta manera no debe preocuparnos, pues no amenaza nuestra libertad: si tiene sentido se asienta entonces en una imagen del mundo en que la libertad es un trasfondo imprescindible, y si pretende plantearse desde fuera de esa imagen del mundo, que es la que todos compartimos, entonces no tiene sentido. "Una duda sin término no es ni siquiera una duda" (Wittgenstein 1988, § 625, p. 83c).

\section{La prioridad de la racionalidad práctica}

El hecho de que quepa imaginar otro mundo diferente del actual no implica en absoluto que dicho mundo sea posible empírica- 
mente, cuando menos de momento. Así, por mucho que seamos capaces de pensar en un mundo como Determinilandia en el que la ciencia desmienta el hecho de que somos seres responsables, esto no quiere decir que dicho mundo sea una alternativa real al mundo en el que actualmente vivimos. En efecto, la alternativa a nuestra forma actual de vida que sería Determinilandia no está a nuestro alcance y, por ello, es cabal defender que su posibilidad lógica no es razón suficiente para que intentemos abandonar la forma de vida que implica la presencia del concepto de responsabilidad moral.

La principal crítica que se le puede hacer a Strawson es que cabe imaginar otro mundo en que las leyes científicas nos den la posibilidad de prescindir de las emociones reactivas y, por lo tanto, donde seamos capaces de prescindir de la idea de responsabilidad moral. Esta crítica lleva consigo una certeza: que no puede darse una solución a priori al problema de la responsabilidad moral. Dicho problema debe resolverse mediante un debate pragmatista sobre la racionalidad práctica de la elección de la continuidad de nuestro mundo actual (en que funcionamos haciendo atribuciones de responsabilidad) o de otro mundo alternativo como Determinilandia, sólo vagamente esbozado por el incompatibilista. De este modo se alcanza la idea de que es indispensable contar con un criterio que nos permita decidir racionalmente qué vida es preferible: si una dominada por juicios de responsabilidad u otra dominada por leyes científicas manejables.

Cabe pensar que si llegásemos a creer que el concepto de responsabilidad moral es irracional y tuviésemos la posibilidad de renunciar a él y a los comportamientos sociales que lleva consigo, entonces lo racional sería optar por esto último. El incompatibilista se halla, como ya sabemos, frente a un conflicto de compromisos: su compromiso con una racionalidad práctica y su compromiso con una racionalidad epistémica. Se puede pensar que ambos compromisos son igualmente importantes, pero que en nuestra situación actual hay más razones para mantener uno y no el otro. Pues bien, en este sentido hay una buena razón para mantener nuestro compromiso con la racionalidad práctica como intentaré mostrar a continuación. 
No contamos con leyes científicas manejables; esto es, las estructuras sociales no nos permiten hoy en día actuar como si el determinismo hubiese de suprimir nuestro actual concepto de responsabilidad moral y nos hiciese prescindir de nuestras emociones reactivas. $\mathrm{O}$ dicho de otro modo: Determinilandia no es posible más que en el terreno especulativo. Por ello podemos afirmar que en nuestros días no hay ninguna incoherencia en la postura compatibilista: mientras nuestro mundo sea el que es, en que contamos con la atribución de responsabilidad como eje de nuestra vida moral, y dicho mundo funcione correctamente, entonces, en ninguno de los dos sentidos de "racional" que hemos distinguido, es irracional mantener nuestro juego de expectativas y de atribución de responsabilidades. Pero sí sería irracional dejar de hacerlo por lo menos desde el punto de vista de la racionalidad práctica. Es más, puede decirse que, ya que nuestro mundo es el que es, ni siquiera es posible elegir; se trata de un juego especulativo más, puesto que dadas las circunstancias es imposible optar por Determinilandia.

El problema de qué hacer o qué no hacer con nuestra vida práctica no puede anticiparse metafísicamente a su posible vigencia práctica; es decir, la sospecha de que podamos estar siendo incoherentes teóricamente al comportarnos como si fuésemos seres responsables no es un argumento suficiente para que abandonemos nuestra forma de vida actual. Para prescindir del trasfondo, del concepto de responsabilidad moral, en que se basa nuestro comportamiento social es necesario contar con otro trasfondo. Deberíamos crear un mundo nuevo parecido a Determinilandia para poder abandonar nuestro compromiso con las emociones reactivas y con nuestro sistema de excusas y exenciones, y por ello dicho compromiso parece esencial, irrenunciable. Sin embargo, no es así: como hemos visto, es lógicamente posible romperlo, no parece factible encontrar un argumento metafísico determinante para rebatir al incompatibilista. No obstante, la cuestión que nos ocupa, como destacó Strawson, tiene una importancia práctica muy superior a su importancia metafísica y por esa razón basta y sobra con el argumento pragmatista de Strawson para rebatir al incompati- 
bilista: mantener nuestro comportamiento responsable con los juicios y emociones que conlleva es lo más racional hoy por hoy. Ceder a las presiones metafísicas del incompatibilista es en todo punto descabellado... y tal vez por ello es un hecho que no hay incompatibilistas que hayan sido capaces de renunciar a sus emociones reactivas y de dejar de participar en el juego de la responsabilidad. Es necesario otro mundo adonde ir para poder abandonar el nuestro, al igual que es necesario un paradigma nuevo para que pueda haber una revolución científica: debe haber cambiado la percepción y la interpretación del mundo, debe haber ciertas evidencias y, además, el nuevo paradigma debe ser "manejable", útil. En el caso del creyente que presenté anteriormente no existe ningún compromiso práctico relevante que anteponer al compromiso teórico, porque en ese dilema se enfrentan dos formas de vidas posibles empíricamente, y por ello no podemos admitir el burdo argumento del creyente. Sin embargo, el problema de la responsabilidad moral es muy diferente.

La razón por la cual no querríamos abandonar nuestro mundo participante es que no poseemos, hoy en día, una teoría científica que nos describa suficientemente bien cómo funciona, de manera determinista, la acción humana. Otra forma de decir lo mismo es sostener que normalmente consideramos que cuando algo está determinado, entonces, si poseemos datos suficientes, es predecible. Pero hoy por hoy no somos capaces de predecir el comportamiento humano más que en muy contadas ocasiones y además de forma vaga e imprecisa, pero no científica. Reiteradamente los seres humanos hemos fracasado cuando hemos intentado predecir el comportamiento ajeno (y el nuestro propio) mediante leyes científicas. Una y otra vez nuestros intentos por adaptar el curso de la historia a leyes ha fracasado, y a menudo de forma sangrienta. Esto no quiere decir que la idea de que algún día la ciencia será capaz de llevar a cabo tamaña hazaña sea descabellada (aunque el fracaso del conductismo y doctrinas similares no cuente a su favor); sin embargo, debemos preguntarnos si es racional, hoy en día, a cuenta de esa sospecha sobre una posibilidad futura, renunciar al trasfondo 
de la responsabilidad moral. Y es aquí donde el argumento pragmatista de Strawson entra en juego con fuerza: no parece racional hacerlo porque ello supondría una gran merma en nuestra calidad de vida, ya que los huecos que dejarían los juicios de expectativas que componen nuestras relaciones sociales no podrían rellenarse con nada. No tenemos ninguna herramienta que nos permita vivir en un mundo diferente de aquel en que nos comportamos como seres responsables. Las cábalas metafísicas del incompatibilista no son esa herramienta, sino meras sospechas. Desde una racionalidad práctica no podemos sino concluir que lo racional es seguir viviendo en nuestro mundo actual, funcionando a base de atribuciones de responsabilidad y excepcionalmente de excusas y exenciones.

\section{Conclusión: una versión pragmatista de la libertad}

Siguiendo a Paul Russell se pueden señalar dos ideas que son esencialmente constitutivas del punto de vista incompatibilista:

[Q]ue si la tesis del determinismo es cierta, entonces tenemos razones para rechazar y repudiar las actitudes y prácticas (establecidas) asociadas a la responsabilidad moral sobre la base de que son incoherentes y están injustificadas.

[Q]ue si tenemos razones para suspender o abandonar las actitudes y prácticas asociadas a la responsabilidad moral, entonces somos, psicológica o prácticamente hablando, capaces de hacer tal cosa. (Russell 1992, p. 289)

Como hemos visto, no podemos negar la segunda instancia porque no hay modo de averiguar aquello de lo que somos o no capaces de forma absoluta. La razón de esta imposibilidad es que el ser humano está muy lejos de ser un animal demasiado natural, lo cual lo hace suficientemente maleable como para que sea muy difícil poner límite a sus capacidades. La ventaja de la perspectiva de Strawson es que deja de lado el asunto metafísico y se fija en lo práctico, en los hechos. La estrategia pragmatista se centra en la primera demanda del incompatibilista: en ella la 
discusión que se abre es de carácter práctico y dentro de ésta una definición pragmatista de la racionalidad resulta victoriosa.

El error clave del incompatibilista es que olvida que nuestro compromiso es con una forma de vida, no con una idea. El problema de la libertad y de la responsabilidad moral no es, o no debería ser, un problema de orden estrictamente metafísico; su interés radica, muy por el contrario, en su íntima relación con la vida. La responsabilidad moral como trasfondo cognitivo es lo que nos permite llevar a cabo nuestra vida tal y como la conocemos, y por ello el problema filosófico de la libertad merece la pena cuando se ocupa de nuestra vida, de las prácticas que se derivan de ese trasfondo que es la idea de libertad. Esa libertad entendida como responsabilidad, como principio activo de nuestra vida moral, como mecanismo efectivo que no sólo fundamenta nuestras acciones y nuestros juicios morales, sino que los hace posibles y está presente en todos y cada uno de ellos.

Así, cabe afirmar que hay dos tipos de libertad: uno metafísico y otro práctico. Aceptar el determinismo sólo podría afectar el primer tipo, nuestra idea filosófica del libre albedrío, pero en ningún caso afecta nuestra forma práctica de vivir y entender la libertad como responsabilidad: "la aceptación del determinismo no sería un cambio en nuestra transacción moral, sino en nuestras definiciones" (Weatherford 1991, p. 234). Sin ir más lejos, en las Meditaciones metafísicas cuando Descartes distingue entre la libertad divina y la libertad humana señala que la diferencia entre ambas estriba en que la primera es indeterminada. En efecto, para la acción divina basta la sola voluntad divina, una voluntad absoluta que decide, desde la indiferencia según Descartes, cómo han de ser las cosas y por ese simple acto las hace necesarias, verdaderas o buenas. El ser humano, por el contrario, no puede evitar asentir ante lo que es verdadero o lo que es bueno una vez que lo reconoce; no hay nada creativo en la decisión humana, se trata más bien de un acto de confirmación de que algo es como es. En todo caso sólo en aquellas ocasiones en que ignoramos qué es verdadero o qué es bueno y entonces suspendemos nuestro juicio y nos 
quedamos en la duda, sólo entonces decimos, obraríamos con indiferencia y sin determinación... y parece un poco triste, por no decir incorrecto, tener que pensar que en eso consistiría realmente ser libre:

la indiferencia no pertenece en absoluto a la esencia de la libertad humana, visto que no somos solamente libres cuando la ignorancia de lo bueno y lo verdadero nos vuelve indiferentes, sino principalmente también cuando el conocimiento claro y distinto de una cosa nos empuja a y nos compromete en su búsqueda". (Descartes 1996, p. 280)

En definitiva: lo propio de la libertad humana es actuar por alguna razón, esto es, desde la determinación.

Entonces, ¿qué es lo que le preocupa al incompatibilista? ¿Qué tipo de libertad reclama? ¿Realmente es importante que seamos libres de no creer que dos y dos son cuatro, de poder decidir si es cierto o no que lo son? ¿Es realmente importante que seamos libres de elegir querer hacer algo que no queremos hacer? El incompatibilista reclama una libertad absoluta, una libertad de un ser que sea causa sui, esa libertad que Descartes atribuye a Dios, y esa libertad claramente nos está vedada a los seres humanos porque es incompatible con cualquier versión del determinismo. Pero, ¿es ésa la libertad que queremos? ¿Qué necesidad tenemos de ser Dios? ¿Qué problema hay en decir de algo que es verdadero porque no podemos más que creer que lo es o de hacer algo porque no podemos sino quererlo hacer? La libertad práctica del ser humano debería bastarnos, la libertad metafísica contracausal de Dios apenas tiene sentido y es estéril desde el punto de vista de la vida humana.

Hay una forma de entender la libertad que merece la pena, que es compatible con el determinismo y que conlleva ciertas prácticas que configuran nuestra vida social: la libertad como responsabilidad. Por ello deberíamos mantener las instituciones que se basan en la responsabilidad moral, porque:

Hacen la vida más tolerable y simpática. Dan textura y valor a nuestra relación con los demás. Añaden predecibilidad y seguridad a la conmoción de nuestras vidas. Por todas estas razones, 
es importante tener instituciones morales. No es importante, y de hecho hasta resulta contraproducente, tener nociones de pecado y culpa absoluta. Estaremos bien descargados de ellas. (Weatherford 1991, p. 235)

Nuestra libertad está mejor dentro de los límites de la razón práctica, y no como una cualidad sobrenatural de carácter absoluto.

\section{BIBLIOGRAFÍA}

Ayer, Alfred. J., 1980, "Free Will and Rationality", en Zak van Stratten 1980, pp. 1-13.

Bennett, Jonathan, 1980, “Accountability”, en Z. van Stratten (comp.), pp. 14-47.

Dennett, Daniel C., 1984, Elbow Room: The Varieties of Free Will Worth Wanting, MIT Press, Cambridge (Mass.).

Descartes, René, 1996, Méditations métaphysiques, edición bilingüe francés/latín, Presses Universitaires de France, París.

Fischer, John M., 1999, "Recent Work on Moral Responsibility", Ethics, vol. 110, pp. 93-139.

Fischer, John M. y Mark Ravizza (comps.), 1993, Perspectives on Moral Responsibility, Cornell University Press, Ithaca.

McKenna, Michael, 1998a, "A Speaker-Meaning Theory of Moral Responsibility", comunicación presentada en el Twentieth World Congress of Philosophy, agosto, Boston (Mass.), pp. 1-9.

— - 1998b, "The Limits of Evil and the Role of Moral Address: A Defense of Strawsonian Compatibilism", Journal of Ethics, vol. 2, no. 2, pp. 123-142.

Russell, Paul, 1992, "Strawson's Way of Naturalizing Responsibility", Ethics, vol. 102, pp. 287-302.

Strawson, Galen, 1986, Freedom and Belief, Clarendon Press, Oxford. Strawson, P.F., 1962, "Freedom and Resentment", en J.M. Fischer y M. Ravizza (comps.), pp. 55-56.

Van Stratten, Zak (comp.), 1980, Philosophical Subjects: Essays Presented to P.F. Strawson, Oxford University Press, Nueva York.

Wallace, Robert J., 1998, Responsibility and the Moral Sentiments, Harvard University Press, Cambridge (Mass.).

Watson, Gary (comp.), 1982, Free Will, Oxford University Press, Oxford. 
Weatherford, Roy, 1991, The Implications of Determinism, Routledge, Londres.

Wittgenstein, Ludwig, 1988, Sobre la certeza, edición bilingüe español/alemán, trad. Josep Lluís Prada y Vicent Raga, Gedisa, Barcelona.

Recibido el 16 de julio de 2003; aceptado el 3 de diciembre de 2003. 